\title{
POTENTIAL OF DUNALIELLA SALINA MICROALGAE TO AMELIORATE HIGH-FAT DIET-INDUCED OBESITY IN ANIMALS' RODENT
}

\author{
FAROUK K EL-BAZ ${ }^{1 *}$, HANAN F ALY ${ }^{2}$ \\ ${ }^{1}$ Department of Plant Biochemistry, National Research Centre, 33 El Bohouth st. (Former El Tahrir st.), Dokki, Giza, Egypt. ${ }^{2}$ Department of \\ Therapeutic Chemistry, National Research Centre, 33 El Bohouth st. (Former El Tahrir st.), Dokki, Giza, Egypt. Email: fa_elbaz@hotmail.com
}

Received: 01 November 2017, Revised and Accepted: 11 December 2017

\section{ABSTRACT}

Objective: This study was carried out to investigate the potential of Dunaliella salina microalgae to ameliorate obesity induced by high-fat diet (HFD) in male Wistar rats.

Methods: Fifty rats weighing 150-160 g were fed HFD for 12 weeks. The rats were randomly divided into five groups of ten rats each. Obese rats were orally administered $D$. salina ethanolic extract ( $150 \mathrm{mg} / \mathrm{Kg}$ body weight), and orlistat as standard drug (12 mg/Kg body weight), for 6 weeks.

Results: Treatment of obese rats with both $D$. salina and orlistat had a significant effect in reducing body and liver weights as well as visceral fat, inhibiting pancreatic lipase activity, decreased lipid profile, and increased fecal fat and ameliorating liver function enzymes activity, insulin, blood glucose, and leptin levels. Besides, food intake was insignificantly increased as a result of D. salina and orlistat treatments compared with normal control rats.

Conclusion: It could be concluded that $D$. salina rich in $\beta$-carotene significantly reduced body weight gain and ameliorated several metabolic pathways implicated in obesity and its related complication. Hence, further intensive study must be carried out to formulate D. Salina extracts to apply as a promising natural anti-obesity nutraceutical drug.

Keywords: Leptin, Obesity, Body weight, Lipid profile, Insulin.

(C) 2018 The Authors. Published by Innovare Academic Sciences Pvt Ltd. This is an open access article under the CC BY license (http://creativecommons. org/licenses/by/4. 0/) DOI: http://dx.doi.org/10.22159/ajpcr.2018.v11i3.23398

\section{INTRODUCTION}

High obesity rate was observed worldwide, especially in developed countries [1,2]. Increasing the intake of total energy in different diet composition may cause the main reason in the development of obesity and its related complications, such as cardiovascular and diabetes. In addition, daily consumption of fast prepared foods in restaurant has been associated with higher body fat. Obesity studies on rats revealed different metabolic patterns dependent on the source of excess energy $[3,4]$.

Fat-rich diet consumption affects lipid profile of the serum and the composition of fatty acids, which is a principle factor in the lipid metabolism improvement. Intake of the high saturated fatty acids elevates the low-density lipoprotein-cholesterol (LDL-c) and decreases the high-density lipoprotein-cholesterol (HDL-c) in the circulation, a condition known as coronary artery disease, because the HDL-c is correlated with the risk of atherosclerosis, while LDL-c is an critical risk marker for cardiovascular conditions, so when found in high levels in the blood, it induces the progress of atherosclerosis [5]. The consumption of high-fat diet may be also connected with triglycerides (TGs) accumulation in the liver and the subsequent non-alcoholic hepatic disease development [5]. Hence, unsaturated fatty acid balance is a principle when carefully choosing sources of food and those monounsaturated and polyunsaturated fatty acids rich, especially, polyunsaturated fatty acids long-chain to mimic atherosclerosis risk.

Adipocyte-secreted factors affect diverse processes including energy balance and appetite, insulin sensitivity, lipid metabolism, and inflammation [6,7]. It has been found that, obesity has been shown to be related more directly to cardiovascular disease than subcutaneous fat [8]. It is known that visceral fat store may be differentially reactive to food composition and may generate factors not yet recognized which may participate in difficulty of maintaining weight loss.
Dunaliella salina Teodorescu (Dunaliellaceae), a green alga species, is one of the richest sources of $\beta$-carotene, a secondary metabolite, and a lipid-soluble orange pigment, used in food and feed as a coloring agent. D. salina normally contains 5-10 mg of ß-carotene per gram dry weight. However, the ratio increases up to $14 \%$ of dry weight in stress conditions such as high salinity, high light intensity, food scarcity, and extreme temperature. ß-carotene exhibits several important biological activities, including preventing coronary heart disease and malignant tumors, increasing cell division of lymphocytes, expanding the immunological response, and controlling of growth [9]. In addition, the antioxidant properties of $ß$-carotene help in eliminating free radicals. Thus, $ß$-carotene, which has applications in several different industrial sectors because of its numerous properties, is of great economic importance [10].

Therefore, the aim of the present study is to investigate the role of D. salina extract on obesity induced by high-fat diet (HFD) through measuring different metabolic parameters including liver function enzyme activities, body weight gain, organ weight, food intake, visceral and fecal fats, blood glucose, insulin, leptin levels as well as pancreatic lipase activity

\section{MATERIAL AND METHODS}

\section{Cultivation of $D$. salina}

The organism was grown in conical flask 5 L containing BG11 nutrient media according to Stanier et al. as presented in Table 1 [11].

$1 \mathrm{ml} / \mathrm{l}$ from the micronutrient was added into the culture medium. After autoclaving and cooling, $\mathrm{pH}$ of medium is about 7 . The culture was harvested by centrifugation at $5000 \mathrm{rpm}$ and dried at $50^{\circ} \mathrm{C}$ and then grounded into homogeneous fine powder. 
Ethanolic extract preparation of $D$. salina

For the preparation of the ethanolic extract, $100 \mathrm{~g}$ of $D$. salina powder was soaked in ethanol (80\%) and shacked on shaker (Heidolph UNIMAX 2010) for $48 \mathrm{~h}$ at $150 \mathrm{rpm}$. The extract was filtered using a Buchner funnel and Whatman No. 4 filter paper, and the algal residue was reextracted with the addition of fresh $80 \%$ ethanol for another 2 times. Combined filtrates were concentrated using Rotary evaporator (Heidolph-Germany) at $40^{\circ} \mathrm{C}$ under vacuum. The resulting dry extract was evaporated on a rotary vacuum evaporator to dryness. The dry extract was stored at $-20^{\circ} \mathrm{C}$ in a freeze and kept for further analysis [12].

\section{Biological assay}

\section{Experimental animals}

Male albino rats $(n=50)$ weighted $150 \pm 20$ g were obtained from the Animal House of the National Research Centre (NRC). Animals were quarantined and allowed to acclimate for 10 days before beginning experimentation. They were housed 10 per cage under temperature controlled environment $\left(26-29^{\circ} \mathrm{C}\right)$ with a fixed light/dark cycle with free access to water and food. All procedures of the present study were performed according to the Ethical Committee of the NRC, Egypt, provided that the animals will not suffer at any stage of the experiment.

\section{Induction of obesity in rats}

Obesity was induced in rats according to the method of Adaramoye et al. [13] by feeding rats high-fat diet (cholesterol), cholesterol was orally administrated at a dose of $30 \mathrm{mg} / 0.3 \mathrm{ml}$ olive oil $/ 1 \mathrm{~kg}$ animal 5 times a week for 12 consecutive weeks, lard fat was mixed with normal diet (ND) ( $1 \mathrm{~kg}$ of animal lard was added to $5 \mathrm{~kg}$ of ND), and the occurrence of obesity was determined by measuring body weight gain percentages, visceral, and fecal fat percentages.

\section{Doses and routes of administration}

Obese rats received an oral dose of $2 \mathrm{mg} / \mathrm{kg}$ body weight dissolved in distilled water of the anti-obesity reference drug, orlistat $(12 \mathrm{mg} / \mathrm{kg})$ for 6 weeks [14]. Orally administered $150 \mathrm{mg} / \mathrm{kg}$ body weight $D$. salina ethanolic extract Ruperez et al. [15] for 6 weeks, respectively.

\section{Determination of body weight gain and food intake}

Body weight change and food intake were measured according to method by Akase et al. [16]. Intake of food was measured weekly on a cage basis and expressed as g of food/day. Initial body weight of all animals was measured before they were fed with either ND or HFD for 12 weeks. At the end of each week, the weight gain (\%) was calculated as follows:

$$
\text { Weight gain } \%=\frac{\text { New weight } \mathrm{W} 1-\text { Initial weight } \mathrm{W} 0}{\text { Initial weight } \mathrm{W} 0} \times 100
$$

\section{Determination of fecal fat content}

Fecal fat content of the rats was determined based on the slightly modified method described by Bligh and Dyer [17] and Tsujita et al. [18]. Briefly, feces $(0.5 \mathrm{~g})$ were soaked in $2 \mathrm{~mL}$ distilled water and homogenized completely. It was then stored at $4^{\circ} \mathrm{C}$ for $24 \mathrm{~h}$ followed by homogenization by vortex for $1 \mathrm{~min}$. Extraction of lipids from feces was executed using $7.5 \mathrm{ml}$ chloroform:methanol (1:2, v: v) for $30 \mathrm{~min}$, followed by the addition of $2.5 \mathrm{~mL}$ of chloroform and deionized water and shaking for another $30 \mathrm{~min}$. Resultant mixtures were then centrifuged at $\times 2000 \mathrm{~g}$ for $15 \mathrm{~min}$; the lipophilic layer was isolated and dried under vacuum.

\section{Food consumption}

Individual body weight gains were recorded before the study imitation (day 0 ) and weekly thereafter. Mean body weight gains were calculated for each group at each interval and for the overall testing interval. During the study, food consumptions were measured weekly per cage and mean food consumptions by individual rats were calculated [14].

\section{Experimental design}

Fifty male Wistar albino rats (5-6 weeks old) weighing at $150.00 \pm 10$ $\mathrm{g}$ (mean $\pm \mathrm{SD}$ ) (weight of rats on the day received from supplier). After adaptation period to the environment, the rats were randomly divided into five groups ( $\mathrm{n}=10 /$ group) as follows:

- Group 1: Normal Diet (ND).

- Group 2: ND and treated with $150 \mathrm{mg} / \mathrm{kg}$ body weight of $D$. salina for 12 consecutive weeks (ND/DS).

- Group 3: HFD treated rats for 12 weeks (obese rats).

- Group 4: Obese rats treated for 6 weeks with $150 \mathrm{mg} / \mathrm{kg}$ body weight of ethanolic extract of $D$. salina (HFD/DS).

- Group 5: Obese rats treated for 6 weeks with anti-obesity standard drug orlistat (12 mg/kg body weight) (HFD/OR).

Health conditions of all rats were monitored daily, and no adverse events were observed throughout the study. At the beginning of the experiments, the weights of all rats were recorded at $150.00 \pm 10.00 \mathrm{~g}$ (mean \pm SD) (weight of rats after 10 days of acclimatization). All experiments and biochemical analysis were conducted using 50 rats with triplicate measurements. The permission to conduct this study was according to the ethics of NRC, Egypt.

Blood sample and collection of serum liver, kidney, heart, visceral fats, and feces

Blood samples were obtained following an overnight fasting state at the end of treatment (week 12) at 8 a.m. Samples were withdrawn from a cubital vein into blood tubes under diethyl ether anesthesia and immediately stored on ice at $4^{\circ} \mathrm{C}$. The serum was then separated from the cells by centrifugation at $3000 \mathrm{rpm}$ for $10 \mathrm{~min}$, and they were stored until analyzing at $-80^{\circ} \mathrm{C}$ [19]. After 12 and 18 weeks of treatment, all the rats were sacrificed. The fats and organs such as the liver, kidney, and heart were also weighed. Feces were collected in the final week of the study for the determination of fecal fat content.

\section{Biochemical measurements}

Various biochemical parameters were measured including lipid profiles of plasma TG, total cholesterol (TC), LDL-c and HDL-c (Biodiagnostic, Egypt), liver enzymes of alanine aminotransferase (ALT), alkaline phosphatase (ALP), aspartate aminotransferase (AST), $\gamma$-glutamyltransferase $(\gamma$-GGT) (Biodiagnostic, Egypt), insulin (Mercodia Rat Insulin enzyme-linked immunosorbent assay [ELISA] Kit, Uppsala, Sweden), and leptin (RayBio Rat Leptin ELISA kit, Norcross, GA, USA, Cat\# ELR-Leptin-001). The concentration of LDL-c was calculated by Friedwald's formula [20]. Whereas, serum cholesterol, TG, and HDL-c were determined using enzymatic colorimetric methods according to Kostner [21]. Serum ALT and AST activity enzymes were estimated according to the method of Reitman and Frankel [22]. ALP was measured by the method of Belfield and Goldberg [23] using a diagnostic kit (Biosystems, Egypt). Serum $\gamma$-GGT activity was measured according to the study described by Persijn and van der Slik [24] using QCA Diagnostic kits (Spain). Pancreatic lipase activity was performed according to Tsuzuki et al. [25].

\section{Percentages changes and improvement}

$$
\text { Percentage change }=\frac{\text { Mean of control }- \text { Mean of test }}{\text { Mean of control }} \times 100
$$

\section{Percentage of improvement

$=\frac{\text { Mean of diseased }- \text { Mean of treated }}{\text { Mean of control }} \times 100$

\section{Statistical analysis}

Data are expressed as mean \pm SDM of 10 rats in each group. Statistical analysis is carried out using SPSS computer program coupled with CO-state computer program, where unshared letters are statistically significant at $\mathrm{p} \leq 0.05$.

\section{RESULTS}

Effects of $D$. salina on percent body weight gain and food intake in obese rats

The present study indicated in Table 2 showed a significant increase in body weight gain in obese rats feed HFD for 12 weeks reached to 
$140.63 \%$, while a significant reduction in body weight gain in obese rats treated with D. salina and orlistat with percentages $29.30 \%$ and $31.16 \%$, respectively. However, an insignificant change was recorded in food intake in obese and obese--treated rats either with D. salina or orlistat standard drug as compared to control (Table 2).

\section{Effects of $D$. salina on percentage of visceral and fecal fats in obese} rats

Table 3 clearly demonstrated a significant increase in visceral fat in obese rats (G3) with percentage $285.81 \%$. While, a significant reduction in visceral fat in obese rats treated with $D$. salina $(138.06 \%)$ was noticed

Table 1: BG11 nutrient composition

\begin{tabular}{|c|c|}
\hline Macronutrient & $\mathrm{mg} / \mathbf{l}$ \\
\hline NaNO3 & 1500.000 \\
\hline $\mathrm{K}_{2} \mathrm{HPO}_{4}$ & 40.000 \\
\hline $\mathrm{MgSO}_{4} .7 \mathrm{H}_{2} \mathrm{O}$ & 75.000 \\
\hline $\mathrm{CaCl}_{2} \cdot 2 \mathrm{H}_{2} \mathrm{O}$ & 36.000 \\
\hline Citric acid & 6.000 \\
\hline $\mathrm{Na}_{2} \mathrm{CO}_{3}$ & 20.000 \\
\hline $\mathrm{Na}_{2}^{2}$ EDTA & 1.000 \\
\hline Ferric ammonium citrate & 6.000 \\
\hline Micronutrient & $\mathrm{g} / \mathrm{l}$ \\
\hline $\mathrm{H}_{3} \mathrm{BO}_{3}$ & 2.860 \\
\hline $\mathrm{MnCl}_{2}^{3} \cdot 4 \mathrm{H}_{2} \mathrm{O}$ & 1.810 \\
\hline $\mathrm{ZnSO}_{4} \cdot 7 \mathrm{H}_{2} \mathrm{O}$ & 0.222 \\
\hline $\mathrm{Na} 2 \mathrm{MoO} 4.2 \mathrm{H} 2 \mathrm{O}$ & 0.390 \\
\hline $\mathrm{CuSO}_{4} \cdot 5 \mathrm{H}_{2} \mathrm{O}$ & 0.079 \\
\hline $\mathrm{Co}\left(\mathrm{NO}_{3}\right)_{2} \cdot 6 \mathrm{H}_{2} \mathrm{O}$ & 0.0494 \\
\hline
\end{tabular}

compared with standard drug (180.00\%). Further, a significant increase in fecal fat was recorded in obese rats with percentage $110.29 \%$, compared to control rats. Obvious increase reached to two-fold increase (324.26\%) and two-fold and half (396\%) in fecal fat in obese rats treated with either with $D$. salina extract or standard drug, respectively.

Organ weights of obese rats treated with $D$. salina for 6 weeks Table 4 indicated a significant increase in liver weight in HFD rats with percentage increase $56.29 \%$. Treatment of obese rats with D. salina or orlistat as reference drug showed a significant reduction in liver weight by $18.47 \%$ and $27.76 \%$, respectively, while insignificant change was detected in cardiac and renal tissues in obese rats compared to normal control one.

Insulin, blood glucose, leptin levels, and pancreatic lipase activity in obese rats treated with $D$. salina for 6 weeks

There was a significant increase in blood glucose, insulin, leptin levels, and pancreatic lipase activity in obese rats (G3) with percentage $79.08,52.00,70.54$, and $240.29 \%$, respectively, compared to control one. Noticeable normalization in insulin level and lipase activity was recorded in treated obese rats with $D$. salina and orlistat. In addition, blood glucose and leptin levels recorded improvement percentages $33.77 \%$ and $45.67 \%$, for glucose, and $116.74 \%$ and $218.93 \%$, respectively, for leptin in obese rats medicated with $D$. salina or orlistat as summarized in Table 5 .

Effect of $D$. salina on liver function enzymes in obese rats for 6 weeks of treatment post-induction with HFD

Table 6 demonstrated an insignificant change in all liver function enzyme activities in normal feed diet rats as compared to untreated control rats, while obese-induced rats (G3) with HFD exhibited a significant increase

Table 2: Effects $D$. salina on percent body weight gain and food intake in obese rats

\begin{tabular}{lllll}
\hline Parameter & Control/ND & Control/ND/DS & HFD & HFD/OR \\
\hline Initial body weight (g) & $155.00^{\mathrm{a}} \pm 5.16$ & $157.00^{\mathrm{a}} \pm 1.44$ & $160.00^{\mathrm{a}} \pm 2.32$ & $389.00^{\mathrm{b}} \pm 9.65$ \\
Final body weight (g) & $195.00^{\mathrm{c}} \pm 4.99$ & $189.00^{\mathrm{c}} \pm 5.00$ & $385.00^{\mathrm{c}} \pm 3.26$ & $385.00 \pm^{\mathrm{b}} 8.88$ \\
Body weight gain (\%) & $+25.81^{\mathrm{i}} \pm 2.88$ & $+20.38^{\mathrm{i}} \pm 0.86$ & $+140.63^{\mathrm{f}} \pm 6.87$ & $-29.30^{\mathrm{j}} \pm 1.66$ \\
Food intake (g/week) & $180.00^{\mathrm{a}} \pm 6.77$ & $179.00^{\mathrm{a}} \pm 2.66$ & $176.00^{\mathrm{a}} \pm 8.54$ & $-31.16^{\mathrm{j}} \pm 0.86$ \\
\hline
\end{tabular}

ND: Normal diet, ND/DS: Rats feed normal diet and treated orally with D. salina extract for 6 weeks. HFD/DS: Rats feed with HFD for 12 weeks and treated orally with D. salina for 6 weeks post-induction. FHD/OR: Rats feed HFD and treated orally for 6 weeks with standard drug orlistat. Statistical analysis is carried out using SPSS computer program, combined with Co-state computer program, where unshared letter is statistically significant at $\mathrm{P} \leq 0.05, \mathrm{D}$. salina: Dunaliella salina

Table 3: Effects of $D$. salina on percentage of visceral and fecal fats in obese rats

\begin{tabular}{|c|c|c|c|c|c|}
\hline Parameter & Control/CND & Control ND/DS & HFD & HFD/DS & HFD/OR \\
\hline Visceral fat (\%) & $1.55^{\mathrm{a}} \pm 0.55$ & $1.54^{\mathrm{a}} \pm 0.06$ & $5.98^{\mathrm{b}} \pm 0.71$ & $3.69^{c} \pm 0.26$ & $3.19^{\mathrm{d}} \pm 0.30$ \\
\hline$\%$ Change & & 0.65 & 285.81 & 138.06 & 105.8 \\
\hline$\%$ Improvement & & - & - & 147.74 & 180 \\
\hline Fecal fat (\%) & $2.72^{\mathrm{a}} \pm 0.25$ & $2.92^{\mathrm{a}} \pm 0.55$ & $5.72 \mathrm{~b} \pm 0.91$ & $11.54^{\mathrm{d}} \pm 0.78$ & $13.50^{\mathrm{e}} \pm 0.96$ \\
\hline$\%$ Change & & 7.35 & 110.29 & 324.26 & 396.32 \\
\hline$\%$ Improvement & & & & 213.97 & 286.04 \\
\hline
\end{tabular}

ND: Normal diet, ND/DS: Rats feed normal diet and treated orally with D. salina extract for 6 weeks. HFD/DS: Rats feed with HFD for 12 weeks and treated orally with D. salina for 6 weeks post-induction. FHD/OR: Rats feed HFD and treated orally for 6 weeks with standard drug orlistat. Statistical analysis is carried out using SPSS

computer program, combined with Co-state computer program, where unshared letter is statistically significant at $\mathrm{P} \leq 0.05, D$. salina: Dunaliella salina

Table 4: Organ weights of obese rats treated with D. salina for 6 weeks

\begin{tabular}{|c|c|c|c|c|c|}
\hline Parameter & ND & ND/DS & HFD & HFD/DS & HFD/OR \\
\hline Liver weight (g) & $6.20^{\mathrm{a}} \pm 0.16$ & $5.70^{\mathrm{a}} \pm 0.40$ & $9.69^{\mathrm{b}} \pm 0.36$ & $7.90^{c} \pm 9.65$ & $7.00^{\mathrm{a}} \pm 8.88$ \\
\hline$\%$ Change & & 8.06 & $56.29+$ & -18.47 & -27.76 \\
\hline \%Improvement & & & & 28.87 & 43.39 \\
\hline *Heart weight (g) & $1.05^{c} \pm 0.09$ & $1.10^{c} \pm 0.09$ & $1.22^{c} \pm 0.16$ & $1.17^{c} \pm 0.26$ & $1.26^{c} \pm 0.20$ \\
\hline *Kidney weight (g) & $2.80^{\mathrm{a}} \pm 0.37$ & $2.69^{\mathrm{a}} \pm 2.66$ & $2.76^{\mathrm{a}} \pm 0.59$ & $2.66^{\mathrm{a}} \pm 0.14$ & $2.67^{\mathrm{a}} \pm 0.10$ \\
\hline
\end{tabular}

ND: Normal diet, ND/DS: Rats feed normal diet and treated orally with D. salina extract for 6 weeks. HFD/DS: Rats feed with HFD for 12 weeks and treated orally with $D$. salina for 6 weeks post-induction. FHD/OR: Rats feed HFD and treated orally for 6 weeks with standard drug orlistat. Statistical analysis is carried out using SPSS computer program, combined with Co-state computer program, where unshared letter is statistically significant at P $\leq 0.05$. Heart and kidney weights showed insignificant change in obese and treated rats compared to control one. Statistical analysis is carried out using SPSS computer program, combined with Co-state computer program, where unshared letter is statistically significant at $\mathrm{P} \leq 0.05, D$. salina: Dunaliella salina 
in all liver function enzymes under investigation. On the other hand, obese rats treated with $D$. salina extract showed marked normalization in liver enzymes activities compared with standard anti-obese drug. However, $\gamma$-GGT showed a significant increase with the percentage of improvement reached to $168.45 \%$

Effect of $D$. salina on lipid profile in obese rats for 6 weeks of treatment post-induction with HFD

Table 7 declared an insignificant change in lipid profile in ND feed rats and treated with ethanol extract of $D$. salina except for HDL-C which showed significant increase (36.49\%), compared with normal control untreated rats. While, HFD (G3) rats recorded a significant increase in all lipid profile biomarkers with percentages 90.65\%, 99.73\%, and $53.64 \%$, respectively, for TC, TG, and LDL-C. While, HDL-C showed a significant reduction (43.87\%), compared to control rats. Meanwhile, obese rats treated with $D$. salina extract showed a significant reduction in $\mathrm{TC}$, TG, and LDL-C compared to obese rats with improvement percentages $59.84 \%, 82.84 \%$, and $39.10 \%$, respectively. However, there was a significant increase in HDL-C (65.77\%), compared to obese rats induced by HFD. More or less similar matched results in lipid profile markers were obtained compared with D. salina.

Table 5: Insulin, blood glucose, leptin levels, and pancreatic lipase activity in obese rats

\begin{tabular}{|c|c|c|c|c|c|}
\hline Parameter & ND & ND/DS & HFD & HFD/DS & HFD/OR \\
\hline Glucose (mg/dl) & $83.20^{\mathrm{a}} \pm 6.16$ & $85.44^{\mathrm{a}} \pm 5.40$ & $149.00^{\mathrm{b}} \pm 3.36$ & $120.90^{c} \pm 3.00-45.31$ & $111.00^{c} \pm 8.88-33.41$ \\
\hline$\%$ Change & - & 2.69 & 79.08 & 33.77 & 45.67 \\
\hline$\%$ Improvement & - & - & - & & \\
\hline Insulin (Ul/U/ml) & $7.25^{c} \pm 0.19$ & $7.10^{c} \pm 0.76$ & $11.02^{\mathrm{d}} \pm 0.16+52.00$ & $8.17^{c} \pm 0.46$ & $8.26^{c} \pm 0.60$ \\
\hline$\%$ Change & - & 2.11 & - & 12.69 & 13.93 \\
\hline$\%$ Improvement & - & - & & 39.31 & 38.07 \\
\hline Lipase (UL) & $12.90^{\mathrm{a}} \pm 2.22$ & $12.60^{\mathrm{a}} \pm 1.00$ & $22.00^{\mathrm{b}} \pm 1.59$ & $14.60^{\mathrm{a}} \pm 1.14+13.18$ & $12.67^{\mathrm{a}} \pm 0.10$ \\
\hline Change $\%$ & - & 2.33 & $70.54+$ & 57.36 & 1.78 \\
\hline \% Improvement & - & - & - & & 72.32 \\
\hline Leptin (ng/ml) & $4.12^{\mathrm{a}} \pm 0.02$ & $3.90^{\mathrm{a}} \pm 0.05-5.33$ & $14.02^{\mathrm{b}} \pm 0.06$ & $9.21^{\mathrm{c}} \pm 0.55-123.54$ & $5.00^{\mathrm{d}} \pm 0.45$ \\
\hline Change $\%$ & - & & $240.29+$ & 116.74 & $21.35-218.93$ \\
\hline
\end{tabular}

$\%$ Improvement

ND: Normal diet, ND/DS: Rats feed normal diet and treated orally with D. salina extract for 6 weeks. HFD/DS: Rats feed with HFD for 12 weeks and treated orally with D. salina for 6 weeks post-induction. FHD/OR: Rats feed HFD and treated orally for 6 weeks with standard drug orlistat. Statistical analysis is carried out using SPSS computer program, combined with Co-state computer program, where unshared letter is statistically significant at $\mathrm{P} \leq 0.05$

Table 6: Effect of $D$. salina on liver function enzymes in obese rats for 6 weeks of treatment post-induction with HFD

\begin{tabular}{|c|c|c|c|c|c|}
\hline Parameter & Control/ND & Control/ND/DS & HFD & HFD/DS & HFD/OR \\
\hline $\operatorname{ALT}(\mathrm{U} / \mathrm{l})$ & ${ }^{\mathrm{a}} 49.00 \pm 0.22$ & ${ }^{\mathrm{a}} 45.77 \pm 3.21$ & b88.12 83.23 & ${ }^{\mathrm{a}} 54.32 \pm 2.90$ & a $53.80 \pm 4.78$ \\
\hline$\%$ Change & & 6.59 & 79.83 & 10.86 & 9.79 \\
\hline$\%$ Improvement & & & & 68.97 & 70.04 \\
\hline AST (U/l) & $\mathrm{a} 44.10 \pm 3.21$ & ${ }^{\mathrm{a}} 43.00 \pm 2.80$ & ${ }^{\mathrm{b}} 62.20 \pm 2.14$ & a $50.11 \pm 3.11$ & c52.42 \pm 1.90 \\
\hline$\%$ Change & & 2.49 & 41.04 & 13.63 & 18.87 \\
\hline$\%$ Improvement & & & & 27.41 & 22.18 \\
\hline$\gamma$-GT $(\mathrm{U} / \mathrm{l})$ & ${ }^{\mathrm{a}} 22.00 \pm 0.77$ & ${ }^{\mathrm{a}} 21.00 \pm 2.71$ & ${ }^{\mathrm{b}} 65.96 \pm 4.16$ & ${ }^{\mathrm{c}} 28.90 \pm 1.0$ & aа $25.06 \pm 0.67$ \\
\hline$\%$ Change & & 4.55 & 199.82 & 31.36 & 13.90 \\
\hline \% Improvement & & & & 168.45 & 185.91 \\
\hline ALP (U/l) & a $80.90 \pm 5.33$ & a $78.90 \pm 3.80$ & b142.04 18.55 & a90.00 \pm 6.10 & a $88.00 \pm 3.15$ \\
\hline$\%$ Change & & 2.47 & 75.57 & 11.25 & 8.78 \\
\hline$\%$ Improvement & & & & 64.33 & 66.74 \\
\hline
\end{tabular}

ND: Normal diet, ND/DS: Rats feed normal diet and treated orally with D. salina extract for 6 weeks. HFD/DS: Rats feed with HFD for 12 weeks and treated orally with D. salina for 6 weeks post-induction. FHD/OR: Rats feed HFD and treated orally for 6 weeks with standard drug orlistat. Statistical analysis is carried out using SPSS computer program, combined with Co-state computer program, where unshared letter is statistically significant at $\mathrm{P} \leq 0.05, \mathrm{D}$. salina: Dunaliella salina

Table 7: Effect of D. salina on lipid profile in obese rats for 6 weeks of treatment post-induction with HFD

\begin{tabular}{|c|c|c|c|c|c|}
\hline Parameter & control/ND & control/ND/DS & HFD & HFD/DS & HFD/OR \\
\hline $\mathrm{TC}(\mathrm{mg} / \mathrm{dl})$ & ${ }^{\mathrm{a}} 122.00 \pm 6.76$ & ${ }^{\mathrm{a}} 126.00 \pm 3.66$ & b232.6 24.45 & ${ }^{\mathrm{d}} 159.60 \pm 5.88$ & ${ }^{\mathrm{e}} 139.88 \pm 6.00$ \\
\hline$\%$ Change & - & 3.28 & 90.65 & 30.82 & 14.66 \\
\hline$\%$ Improvement & & & & 59.84 & 76.00 \\
\hline HDL-C (mg/dl) & a $35.90 \pm 1.20$ & b $49.00 \pm 10.10$ & ${ }^{c} 20.15 \pm 9.10$ & $\mathrm{~d} 43.80 \pm 7.44$ & е $30.97 \pm 2.10$ \\
\hline$\%$ Change & & 36.49 & 43.87 & 22.00 & 13.73 \\
\hline$\%$ Improvement) & & & & 65.77 & 30.14 \\
\hline $\mathrm{TG}(\mathrm{mg} / \mathrm{dl})$ & a96.33 \pm 2.44 & a96.00 \pm 2.97 & 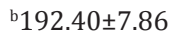 & ${ }^{\mathrm{d}} 112.60 \pm 6.80$ & ${ }^{\mathrm{a}} 100.00 \pm 3.00$ \\
\hline$\%$ Change & & 0.34 & 99.73 & 16.89 & 3.80 \\
\hline$\%$ Improvement & & & & 82.84 & 95.92 \\
\hline LDL-C (mg/dl) & ${ }^{\mathrm{a}} 110.00 \pm 2.88$ & a $100.00 \pm 4.00$ & b $169.00 \pm 2.00$ & $\mathrm{a} 126.00 \pm 4.77$ & ${ }^{c} 129.00 \pm 9.00$ \\
\hline$\%$ Change & & 0 & 53.64 & 14.55 & 17.27 \\
\hline$\%$ Improvement & & & & 39.10 & 36.36 \\
\hline
\end{tabular}

ND: Normal diet, ND/DS: Rats feed normal diet and treated orally with D. salina extract for 6 weeks. HFD/DS: Rats feed with HFD for 12 weeks and treated orally with D. salina for 6 weeks post-induction. FHD/OR: Rats feed HFD and treated orally for 6 weeks with standard drug orlistat. Statistical analysis is carried out using SPSS computer program, combined with Co-state computer program, where unshared letter is statistically significant at $\mathrm{P} \leq 0.05$ 


\section{DISCUSSION}

Obesity is defined as an elevation in adipose tissue mass and results in a higher risk for cardiovascular, non-insulin-dependent diabetes metabolic diseases, and stroke as well as an increased morbidity incidence [14]. Our results demonstrated that the rats in normal (G1) and HFD (G3) groups gained weight throughout the experimental period when compared to the initial body weight, while a significant decrease was observed post-treatment with D. Salina or Orlistat groups (G4) and group (G5), respectively, when compared to G1. Besides, there was an insignificant change of food intake in HFD group when compared to normal and other groups. It was suggested that $D$. salina may be act as orlistat which may be minimally absorbed from the gastrointestinal tract, promotes significant weight loss when used in the treatment of hypoenergetic diet, and lowers blood lipid concentrations [26]. However, there was a significant increase in weight of hepatic tissue in obese rats induced by HFD with percentage $56.29 \%$. Marked reduction in liver weight by $18.47 \%$ and $27.76 \%$ post treatment of obese rats with $D$. salina or orlistat. These results are in contradictory with the findings of Abdul Rahman et al. [27] who declared insignificant change in liver, kidney, and heart weights. The rise in the weight of liver may be related to the accumulation of lipid droplets in hepatic cells [5].

Results of the serum pancreatic lipase activity showed that there was inhibition in G4 and G5 groups comparing with G3 which recorded a significant increase in enzyme activity. On the other hand, D. salina may be act as gastrointestinal lipases, mainly pancreatic lipase, which is important for the TG hydrolysis to free fatty acids in the gut lumen, through reduction in the dietary fat absorption by more than $30 \%$, thereby causes loss of weight near to or more than that get by putting an individual on a fat-limited diet [14].

Higher values of serum lipid profile were observed in G3 when compared to the G1. There was a significant increase in TG, TC, and LDL-c levels in G3, while HDL-c decreased significantly when compared with G1. However, there was a significant reduction in TG, TC, and LDL-C levels, while noticeable elevation in HDL-C in G4 and G5 when compared with G3. However, comparing results of HDL-C level and LDL-C level between G3, G4, and G5 showed that there was a significant increase in HDL-C level in G4 and G5 while opposite results seen in LDL-c level. Besides, there was a significant reduction in TG level and TC in G4 and G5 when compared to G3, respectively. These results indicated that $D$. salina has better ameliorating effects than standard drug on TG and TC, through pancreatic lipase inhibitors that change balance of energy by lowering TG and cholesterol absorption from the gastrointestinal tract as described by Shalaby et al. [14] which may be through the microalgae binding to the lipase active site serine residue [28]. Pancreatic lipase is concerned with absorption of TG from the small intestine to the enterocytes, and if this initial TG movement mechanism is blocked, we can prevent hyperlipidemia. Thus, lipase inhibitor helps to restrict intestinal fat absorption and could be documented as an important therapy for hyperlipidemia and a promise as anti-obesity agents.

The current research measured the efficacy of $D$. salina on the gain of body weight, food intake, glucose level, lipid profile, liver function enzymes, hepatic lipase, and leptin since these microalgae rich in omega-3 fatty acids which is connected with low rate of cardiovascular diseases [2931]. The high levels of serum TC in rats feed HFD may be related to the high lipid intake which is concerned also with the reduction in HDL- C since the anti-atherogenic fraction was altered by the experimental HFD [5]. Further, a diet rich in lipid is linked with the plasma glucose elevated levels [5]. Treatment of obese rats with $D$. salina modulated high glucose level which may be due to $D$. salina contains high fiber content which is concerned with blood glucose level improvement, since fiber may encourage low absorption of intestinal glucose [29-31].

Suppression in the activity of pancreatic lipase and the greater of lipolysis is being considered the promising ways in controlling body weight [32]. The current research declared that restriction in the lipid absorption from intestine may be the effective mechanism by which the $D$. salina ethanolic extract may prevent weight gain in the HFD-fed rats $[32,33]$. Thus, in the present study, the potential of $D$. salina to enhance fecal fat excretion and subsequently excretion of fecal fat energy explained the observed reduction in body weight gain of the medicated rat. The presence of hypolipidemic compounds in D. salina [29-31] may be, therefore, affects dynamics of lipid and consequently prevents developing obesity of medicated rats. The lowering effect of $D$. salina on TG, TC, and LDL-C might be related to a reduction in the absorption of intestinal tract dietary cholesterol and/or cholesterol synthesis interference. It was demonstrated that the dietary fats absorption inhibition restricts the excess energy need for the fats storage in adipose tissue, which was detected with the marked visceral fats suppression in the treated rats. Hence, it could be speculated that the amelioration in the levels of lipid profiles was related in partially to the phytochemical contents of D. salina [29-31].

A recent study of Safafar et al. [34] showed different classes of flavonoids, such as isoflavones, flavanones, flavonols, and dihydrochalcones in microalgae. Quercetin has been proved to show activities as antioxidant and anti-obesity in animal models [35,36]. In other research, chlorogenic acid markedly improving body weight, lipid metabolism, and obesity-related hormone levels in obese mice [37].

The present data indicated that HFD in G3 increased serum AST, ALT, ALP, and ${ }^{\mathrm{P}}$ - GGT enzymes significantly as compared to G1. Treatment of obese rats with $D$. salina showed a significant decrease in the previous parameters compared with G3. It has been suggested that HFD may play principle effect in the fatty liver disease pathogenesis [5]. The highest concentration of fat in the diet increased accumulation of the hepatic TG in animals model, thus confirming fat accumulation in liver cells and increased cell membrane permeability leading to enzyme leakage into circulation [38].

The ameliorative effects of $D$. salina on hepatic enzyme activities may be related to antioxidant effects of carotenoids and high content of omega- 3 fatty acids that could be beneficial in preventing oxidative stress which play a role in liver injury by inducing synthesis of glutathione, an important mediator against hepatocellular injury, hence modulating liver function activities [29-31]. The lower blood glucose post-treatment of obese rats with $D$. salina extract may be due to its effect on estrogen [39].

The present study also showed that the serum leptin has a significant increase in response to HFD as compared with G1 [14]. It has been demonstrated that leptin is provided by adipose tissue to signal fat storage reserves in the body and mediates long-term appetitive controls (to eat more when fat storages are low and less when fat storages are high) [14]. Leptin plasma concentration and mRNA expression in adipose tissue are contributed to obesity severity, as an increase of fat mass is linked with an increase of leptin which performs leptin maker of the total fat mass [40]. Higher leptin levels in the serum of male rats are attributed to the heavier body weight or the androgen, male hormone [41]. Further, the leptin level variation is not always in run parallel with the extent of body fat [39].

In addition, HFD led to rapid resistance of leptin Singh et al. [42] and the resistance of leptin might cover the effects of leptin on the obese conditions [39]. The results of the current research declared general metabolic status amelioration after medication of obese rats with $D$. salina. In this study, leptin levels in the D. salina treated group were found to decrease by $123.54 \%$, in accordance with the reduction in mass of visceral fat and body weight. This is may be due to the induced leptin resistance in the obese rats. Furthermore, reduction in the level of insulin post-treatment of obese rats with $D$. salina has been well known to play a principle role in demonstrating leptin level [39]. 


\section{CONCLUSION}

It could be concluded that $D$. salina significantly reduced weight gain. It is also willing to demonstrate that there were no signs of diarrhea or other abnormal symptoms or bowel activities in the medicated rats, supposing that $D$. salina has no undesired effects as opposed to the orlistat, reference drug of obesity, whereby symptoms of diarrhea and abdominal inconvenience have been previously reported. Most importantly, $D$. salina supplementation at the usage dosages did not influence hepatic functions, suggesting that the dosages used safe for the medication. This result was ascertained by acute oral toxicity study on ethanolic extract of $D$. salina that provided no noticeable signs of toxicity or death up to $5000 \mathrm{mg} / \mathrm{kg}$ body weight for 3 days of the study.

\section{ACKNOWLEDGMENT}

This work was supported and funded by the project entitled "Biodiesel production from algae as a renewable energy source." Funding organization: Research Development and Innovation programme (RDI), Funding Program: EU-Egypt Innovation Fund, 2014-2017.

\section{REFERENCES}

1. Cowie CC, Rust KF, Byrd-Holt DD, Eberhardt MS, Flegal KM, Engelgau MM, et al. Prevalence of diabetes and impaired fasting glucose in adults in the U.S. population: National health and nutrition examination survey 1999-2002. Diabetes Care 2006;29:1263-8.

2. Ogden CL, Carroll MD, Curtin LR, McDowell MA, Tabak CJ, Flegal KM. Prevalence of overweight and obesity in the United States, 19992004. JAMA 2006;295:1549-55.

3. Dourmashkin JT, Chang GQ, Gayles EC, Hill JO, Fried SK, Julien C, et al. Different forms of obesity as a function of diet composition. Int $\mathrm{J}$ Obes (Lond) 2005;29:1368-78

4. Marjani A. A review on the role of triglyceride in metabolic syndrome. Asian J Pharm Clin Res 2015;8:1-3.

5. Aguilar EC, Queiroz MG, Oliveira DA, Oliveira NJ. Serum lipid profile and hepatic evaluation in mice fed diet containing pequi nut or pulp (Caryocar brasiliense Camb.). Ciênc Tecnol Aliment 2011;31:879-83.

6. Rajala MW, Scherer PE. Minire view: The adipocyte-at the crossroads of energy homeostasis, inflammation, and atherosclerosis. Endocrinology 2003; 144:3765-73

7. Sireesha K, Rao PS. Oxidative stress and diabetes: An overview. Asian J Pharm Clin Res 2015;8:15-9.

8. Pouliot MC, Després JP, Lemieux S, Moorjani S, Bouchard C, Tremblay $\mathrm{A}$, et al. Waist circumference and abdominal sagittal diameter: Best simple anthropometric indexes of abdominal visceral adipose tissue accumulation and related cardiovascular risk in men and women. Am J Cardiol 1994;73:460-8.

9. Del Campo JA, García-González M, Guerrero MG. Outdoor cultivation of microalgae for carotenoid production: Current state and prospectives. Appl Microbiol Biotechnol 2007;74:1163-4.

10. Cakmak YS, Kaya M, Asan-Ozusaglam M. Biochemical composition and bioactivity screening of various extracts from Dunaliella salina, a green microalga. EXCLI J 2014;13:679-90.

11. Stanier RY, Kunisawa R, Mandel M, Cohen-Bazire G. Purification and properties of unicellular blue-green algae (order Chroococcales). Bacteriol Rev 1971;35:171-205.

12. Liang H, He J, Ma AG, Zhang PH, Bi SL, Shi DY, et al. Effect of ethanol extract of alga Laurencia supplementation on DNA oxidation and alkylation damage in mice. Asia Pac J Clin Nutr 2007;16 Suppl 1:164-8.

13. Adaramoye O, Akinatyo O, Achen J, Michel A. Lipid lowering effects of methanolic extracts of Vernonia amygdalina leaves in rats fed on high cholesterol diet. Vasc Health Risk Manag 2008;4:235-41.

14. Shalaby HM, Tawfek NS, Abo-El Hussein BK, Abd El-Ghany MS. The Assessment of some biochemical and immunological effects by amphetamine and Orlistat on obesity in rats. Food and Public Health 2014:4:185-92.

15. Ruperez FJ, Garcia-Martinez D, Baena B, Maeso N, Cifuentes A, Barbas C. Evolution of oxidative stress parameters and response to oral vitamins $\mathrm{E}$ and $\mathrm{C}$ in streptozotocin-induced diabetic rats. J Pharm Pharmacol 2008;60:871-8.

16. Akase T, Shimada T, Terabayashi S, Ikeya Y, Sanada H, Aburada M, et al. Antiobesity effects of Kaempferia parviflora in spontaneously obese Type II diabetic mice. J Nat Med 2011;65:73-80.

17. Bligh EG, Dyer WJ. A rapid method of total lipid extraction and purification. Can J Biochem Physiol 1959;37:911-7.

18. Tsujita T, Takaichi H, Takaku T, Aoyama S, Hiraki J. Antiobesity action of epsilon-polylysine, a potent inhibitor of pancreatic lipase. J Lipid Res 2006;47:1852-8.

19. Selek S, Aslan M, Nazligul Y. Serum PON1 activity and oxidative stress in non-alcoholic fatty liver disease. J Harran Univ Med Fac 2012;3:85-91.

20. Fruchart GG. LDL-cholesterol determination after separation of low density lipoprotein. Rev Fr Lab 1982;103:7-117.

21. Kostner GM. Enzymatic determination of cholesterol high density lipoprotein fraction prepared by polyanion precipitation. Clin Chem 1976;22:695.

22. Reitman S, Frankel S. Determination of glutamate pyruvat transaminase and glutamate oxaloacetate transaminase. Am J Clin Path 1957;28:56-63.

23. Belfield A, Goldberg D. Colorimetric determination of alkaline phosphatase activity. Enzyme 1971;12:561-6.

24. Persijn JP, van der Slik W. A new method for the determination of gamma-glutamyltransferase in serum. J Clin Chem Clin Biochem 1976;14:421-7.

25. Tsuzuki W, Ue A, Nagao A, Endo M, Abe M. Inhibitory effect of lysophosphatidylcholine on pancreatic lipase-mediated hydrolysis in lipid emulsion. Biochim Biophys Acta 2004;1684:1-7.

26. Tripathi YC, Shukla P, Tewari DE. Phytochemical evaluation and antihyperglycemic effects of Elaeocarpus ganitrus Roxb (Rudraksha) in streptozotocin induced diabetes. Int J Pharm Pharm Sci 2014;7:280-3.

27. Rahman HA, Sahib NG, Saari N, Abas F, Ismail A, Mumtaz MW, et al. Anti-obesity effect of ethanolic extract from Cosmos caudatus Kunth leaf in lean rats fed a high fat diet. BMC Complement Altern Med 2017; 17:122.

28. Okoro IO, Umar IA, Atawodi SE, Anigo KM. Bioassay-guided evaluation of the antidiabetic activity of Cleome Rutidosperma Dc. Int J Pharm Pharm Sci 2014;7:198-202.

29. Perkins ND. Integrating cell-signalling pathways with NF-kappaB and IKK function. Nat Rev Mol Cell Biol 2007;8:49-62.

30. Zhu YH, Jiang JG. Continuous cultivation of Dunaliella salina in photobioreactor for the production of $\beta$-carotene. European Food Res Technol 2008;227:953-9.

31. Chitranjali T, Chandran PA, Kurup GM. Omega-3 fatty acid concentrate from Dunaliella salina possesses anti-inflammatory properties including blockade of NF- $\mathrm{KB}$ nuclear translocation. Immunopharmacol Immunotoxicol 2015;37:81-9.

32. Yang DJ, Chang YY, Hsu CL, Liu CW, Lin YL, Lin YH, et al. Salacia reticulate and its polyphenolic constituents with lipase inhibitory and lypophilic activities have mild anti-obesity effects in rats. J Nutr 2002;132:1819-24

33. Ibarra A, Cases J, Roller M, Chiralt-Boix A, Coussaert A, Ripoll C, et al. Carnosic acid-rich rosemary (Rosmarinus officinalis L.) leaf extract limits weight gain and improves cholesterol levels and glycaemia in mice on a high-fat diet. Br J Nutr 2011;106:1182-9.

34. Safafar H, van Wagenen J, Møller P, Jacobsen C. Carotenoids, phenolic compounds and tocopherolscontribute to the antioxidativeproperties of some microalgae species grown on industrial waste water. Mar Drugs 2015;13:7339-56.

35. Rivera L, Morón R, Sánchez M, Zarzuelo A, Galisteo M. Quercetin ameliorates metabolic syndrome and improves the inflammatory status in obese zucker rats. Obesity (Silver Spring) 2008;16:2081-7.

36. Kobori M, Masumoto S, Akimoto Y, Oike H. Chronic dietary intake of Quercetin alleviates hepatic fat accumulation associated with consumption of a western-style diet in C57/BL6J mice. Mol Nutr Food Res 2011;55:530-40.

37. Cho AS, Jeon SM, Kim MJ, Yeo J, Seo KI, Choi MS, et al. Chlorogenic acid exhibits anti-obesity property and improves lipid metabolism in high-fat diet-induced-obese mice. Food Chem Toxicol 2010;48:937-43.

38. Williams KH, Vieira De Ribeiro AJ, Prakoso E, Veillard AS, Shackel NA, Brooks B, et al. Circulating dipeptidyl peptidase-4 activity correlates with measures of hepatocyte apoptosis and fibrosis in nonalcoholic fatty liver disease in Type 2 diabetes mellitus and obesity: A dual cohort cross-sectional study. J Diabetes 2015;7:809-19.

39. Hayatdavoudi P, Ghasemi M, Zendehbad B, Soukhtanloo M, Golshan MS, Hadjzadeh MA. Effect of exogenous leptin on serum levels of lipids, glucose, renal and hepatic variables in both genders of obese and streptozotocin-induced diabetic rats. Iran J Basic Med Sci 2015;18:1072-8

40. Lopez IP, Milagro FI, Marti A, Moreno-Aliaga MJ, Martinez JA, De Miguel C, et al. High-fat feeding period affects gene expression in rat white adipose tissue. Mol Cell Biochem 2005;275:109-15. 
41. Haghshenas R, Jafari M, Ravasi A, Kordi M, Gilani N, Shariatzadeh $\mathrm{M}$, et al. The effect of eight weeks endurance training and high-fat diet on appetite-regulating hormones in rat plasma. Iran J Basic Med Sci 2014;17:237-43.
42. Singh KA, Boozer CN, Vasselli JR, Kimberly A. Physiological regulation of appetite: Acute insulin induced elevations of circulating leptin and feeding inhibition in lean but not obese rats. Am J Physiol Regul Integr 2005;10025:373-9. 